\begin{tabular}{|l|l|}
\hline & \\
&
\end{tabular}

SEÇÃO: ARTIGO

\title{
A crítica de Hegel à Filosofia Moral kantiana depois de Rawls
}

\author{
Hegel's critique of Kantian Moral Philosophy after Rawls
}

\section{Thadeu Weber ${ }^{1}$}

orcid.org/0000-0001-8826-7161

weberth@pucrs.br

Recebido em: 11 mar. 2021 Aprovado em: 9 jul. 2021.

Publicado em: 3 set. 2021.

\section{(c) (1)}

Artigo está licenciado sob forma de uma licença Creative Commons Atribuição 4.0 Internacional.
Resumo: O artigo visa mostrar que a critica de Hegel à Filosofia Moral kantiana, a partir a interpretação de Rawls, deve ser revista em alguns aspectos, tais como: a aplicação do imperativo categórico; o problema do formalismo e o próprio construtivismo moral em Kant. Uma reconstrução dos principais aspectos da interpretação rawlsiana da Filosofia prática de Kant é necessária, considerando a crítica hegeliana. Essa é explicitada tendo em vista os avanços que ela representa dentro de uma perspectiva dialética e de possiveis reparos que a ela podem ser feitos.

Palavras-chave: Imperativo categórico. Formalismo. Procedimento. Valor moral. Dialética.

Abstract: The article aims to show that Hegel's critique of Kantian Moral Philosophy, based on Rawls' interpretation, must be revised in some aspects, such as: the application of the categorical imperative; the problem of formalism and Kant's moral constructivism itself. A reconstruction of the main aspects of Rawlsian interpretation of Kant's practical Philosophy is necessary, considering Hegel's critique. This is explained in view of the advances it represents within a dialectical perspective and the possible repairs that can be made to it.

Keywords: Categorical imperative. Formalism. Procedure. Moral value. Dialectic.

\section{Introdução}

O debate entre dois clássicos da Filosofia Prática - Kant e Hegel - é conhecido pelas suas diferenças de fundamentação e justificação. A crítica consequencialista de Hegel ataca de frente o chamado formalismo da moral kantiana. Já tenho dedicado em outro estudo uma análise dessas divergências. ${ }^{2}$ Não se trata, aqui, de fazer uma reconstrução das principais teses da Filosofia Moral de Kant, nem das criticas de Hegel, a não ser enfocá-las a partir de um dos maiores expoentes da Filosofia Prática Contemporânea, o neokantiano J. Rawls. Como ler e entender Kant e a crítica de Hegel, a partir da interpretação e da aplicação do imperativo categórico feitas por Rawls? Como reler a crítica ao formalismo kantiano? Como a dialética rompe com esse formalismo?

O intuito, no artigo, é rever algumas das críticas de Hegel a Kant, inspirado, sobretudo, na interpretação de Rawls do imperativo categórico e suas formulações, o que poderiamos chamar de interpretação procedimentalista de Rawls, bem como do construtivismo moral kantiano. 
Para tal intento, torna-se necessária uma breve análise das principais contribuições do filósofo americano na explicitação da doutrina moral de Kant. É dada uma ênfase ao tema das aplicações do imperativo categórico, por ser esse um dos principais alvos da crítica de Hegel. A acusação de "vazio formalismo" fixa-se em boa medida na primeira formulação do mesmo, embora atinja toda teoria moral do autor. O segundo aspecto é dedicado à análise de alguns elementos da crítica de Hegel à Filosofia Moral do filósofo de Königsberg. Princípios da Filosofia do Direito e Sobre as maneiras de tratar cientificamente o direito natural são as obras objeto de exame. Em terceiro lugar, é feita uma avaliação dessa crítica hegeliana a partir de alguns aspectos da leitura rawlsiana de Kant. O intuito é propor uma certa reatualização das principais teses da Filosofia Moral kantiana motivada pela crítica de Hegel, dentro de uma perspectiva dialética. A esquerda hegeliana, principalmente Marx, irá se beneficiar enormemente dessa perspectiva. Com isso se pretende ter trazido alguma contribuição para a elucidação do referencial teórico do Serviço Social de forte influência hegeliano-marxista.

\section{A interpretação rawlsiana da Filosofia Moral de Kant}

Para se avaliar a pertinência ou não da crítica de Hegel à Filosofia Moral de Kant em muito contribui a distinção de Rawls entre lei moral, imperativo categórico e o procedimento do imperativo categórico (RAWLS, 2005, p. 192). ${ }^{3}$ A lei moral é uma "ideia da razão"; se aplica a todos os seres razoáveis e racionais, inclusive a Deus (RAWLS, 2005, p. 192). O imperativo categórico diz respeito apenas aos "seres finitos e imbuidos de necessidades". Somente seres humanos precisam de imperativos, pois precisam fazer frente às suas paixões. O imperativo categórico mostra como a lei moral se aplica a eles. O procedimento do imperativo categórico refere-se às circunstâncias em que o imperativo categórico é aplicado e precisa adaptar-se a uma determinada situação. Escreve o autor: "Para que o imperativo categórico se aplique à nossa situação, precisa adaptar-se às nossas circunstâncias na ordem da natureza" (RAWLS, 2005, p. 193). Saliente-se que Rawls fala em situação, circunstâncias e leis da natureza. Isso envolve diretamente a primeira formulação e as aplicações do imperativo categórico, embora discuta longamente a segunda formulação - a da dignidade (o homem como fim em si mesmo) - e a terceira - a da autonomia (o reino dos fins).

Diante disso, o que significaria falar em formalismo? Terá Hegel levado em consideração exatamente esses aspectos? Terá levado em conta todas as formulações do imperativo categórico, sobretudo a que se refere ao ser humano como fim em si mesmo e a que diz respeito à autonomia? (KANT, 1974b, seção II).

Rawls dá ênfase ao procedimento do imperativo categórico e o faz em quatro passos. O intuito é mostrar como ele se aplica à nossa situação levando em conta determinadas circunstâncias.

O primeiro passo trata da máxima do sujeito agente, como princípio subjetivo do querer. Supõe-se que seja racional, considerando a situação do agente e as alternativas disponiveis. Supõe-se, também, que a máxima seja sincera, ou seja, indique razões reais e bem pensadas por parte do agente. Espera-se que ele tenha considerado as caracteristicas de suas circunstâncias, com razoabilidade. Assim, temos: "Devo fazer $X$ nas circunstâncias $C$ a fim de realizar $Y$ a menos que Z" (RAWLS, 2005 , p. 194). Tomando o exemplo da promessa enganosa, aplicada ao passo 1 temos: "Devo fazer uma promessa enganosa nas circunstâncias C" (quais sejam: estou em dificuldades financeiras e preciso de dinheiro emprestado, prometo devolvê-lo mesmo sabendo que não terei condições para tal).

O segundo passo refere-se à generalização do primeiro passo. A lei prática é o resultado da máxima que passou pelo teste do procedimento do imperativo categórico. Ela, então, é válida para todo ser racional. Assim reza o passo 2: "Todos

\footnotetext{
3 Sobre o imperativo categórico e suas formulações, ver: Fundamentação da Metafísica dos Costumes (KANT, 1986, seção II); Ética e Filosofia do Direito: autonomia e dignidade da pessoa humana (WEBER, 2013, cap. 1); História da Filosofia Moral (RAWLS, 2005, cap. II a IV); e The Categorical Imperative (PATON, 1974).
} 
devem fazer $X$ nas circunstâncias $C$ a fim de realizar Y a menos que Z" (RAWLS, 2005, p. 194). Aplicado ao exemplo da promessa enganosa, temos: "Todos devem fazer uma promessa enganosa nas circunstâncias C" (RAWLS, 2005, p. 194). Temos, então, uma lei que vale para todos.

O terceiro passo indica a passagem do preceito universal do passo 2 para uma lei da natureza. "Todos sempre fazem $X$ nas circunstâncias $\mathrm{C}$ a fim de realizar Y, como se por uma lei da natureza". No exemplo da mentira temos o correspondente ao passo 3: "Todo fazem (ou tentam fazer) uma promessa enganosa em circunstâncias $\mathrm{C}$, etc. (como por uma lei da natureza)". Nesse passo a mentira universalizada é elevada ao status de lei da natureza.

O quarto passo associa a lei da natureza resultante do terceiro passo às demais leis da natureza já existentes. Ocorre que uma nova ordem natural resulta do acréscimo da lei originária do passo 3 às outras leis da natureza. Essa nova ordem natural é chamada por Rawls de "mundo social ajustado". A questão é: como se comporta a nova ordem natural com a associação da nova lei? Poderíamos ainda falar em mundo social ajustado? No caso do exemplo da promessa enganosa nesse passo 4 devemos associar a lei da natureza do passo 3 "todos fazem uma promessa enganosa", às demais leis da natureza. A pergunta que devemos fazer é: gostariamos de fazer parte de um mundo em que a mentira fosse lei universal, junto com as outras leis naturais? Poderiamos querer pertencer a esse mundo?

A resposta de Kant, na interpretação de Rawls, seria essa: se não pudermos querer pertencer a esse mundo onde a promessa enganosa é uma lei, então não podemos agir segundo aquela máxima do passo 1. Ou seja, esse mundo social ajustado é um mundo no qual ninguém pode fazer uma promessa enganosa nas circunstâncias C. Essa nova ordem natural se desajustaria com a mentira universalizada. Se a promessa enganosa viesse a ser uma lei isso se tornaria público e ninguém mais acreditaria em ninguém. Teriamos, então, um mundo social desajustado e desequilibrado. A mentira universalizada não se ajusta às outras leis da natureza.
O ponto aqui é que não podemos desvencilhar a possibilidade da promessa enganosa das circunstâncias $\mathrm{C}$, referidas no primeiro passo. Mas se as circunstâncias fossem outras? Um novo teste de universalização precisa ser feito. Mas então o dever de dizer a verdade não vale aprioristicamente? A interpretação mais difundida de Kant é a de que ele estaria separando forma e conteúdo. A lei moral valeria independentemente do contexto (conteúdo, circunstâncias). Logo, não poderiamos mentir nunca. Com a crítica de Hegel e a interpretação de Rawls abre-se uma outra perspectiva. Na aplicação do imperativo categórico é dada a ênfase às circunstâncias e, portanto, a crítica ao formalismo deve ser revista. O ideal (o dever-ser) é não mentir nunca, mas na aplicação (no real), tendo em vista as circunstâncias, às vezes é permitido.

O que chama atenção nessa leitura é a importância dada à distinção entre o imperativo categórico e o procedimento do imperativo categórico e, com isso, ao destaque às "circunstâncias C". Aqui está um dos pontos centrais: levar ou não em consideração as circunstâncias, no teste da universalização. As circunstâncias são ou não relevantes na avaliação do valor moral das ações? Kant não defendia exatamente que o imperativo categórico valia independentemente das circunstâncias? Afinal, a lei moral se aplica, considerando as circunstâncias ou vale independente delas? A verdade sempre deve ser dita ou em determinadas circunstâncias pode ser evitada? Não deveriamos falar em validade apriorística do princípio segundo o qual "é um dever dizer a verdade"? (KANT, 1986, p. 173). Isso poderia não valer em certas circunstâncias? A mentira contada a um assassino a fim de proteger um inocente, é permissivel? A insistência nas circunstâncias indica a fundamental relevância que a aplicação do imperativo categórico tem com relação às situações concretas. Se existirem circunstâncias em que a verdade não precisa ser dita, isso não invalida o princípio de que é um dever dizer a verdade.

Além do mais, não se pode deixar de destacar a interpretação rawlsiana da terceira formulação do imperativo categórico - a do reino dos fins. 
Ao poder querer que uma máxima se torne lei universal, exercemos a função de legisladores para uma comunidade moral. Portanto, o conteúdo moral - as normas de ação - não são dadas, mas construidas. É o que Rawls chama de construtivismo moral. ${ }^{4}$ Não há, pois, uma mera justificação de normas já existentes, mas uma construção de novas e sua justificação.

Outra questão diz respeito à necessidade de que uma ação moral, na perspectiva kantiana, seja desprovida de interesses. Segundo a interpretação de Rawls, para Kant "toda a ação é movida por algum interesse". Ele "nunca postulou uma ação realizada exclusivamente segundo a razão, se a entendermos como uma ação desprovida de um interesse que a mova" (RAWLS, 2005. p. 5). Rawls dá um destaque ao fato de que toda ação tem um "objeto ou objetivo". Isso a vincula a algum tipo de interesse. Daí a importância de se avaliar a procedência da crítica hegeliana de uma ética formalista e pouco realista. Certamente não são os interesses que conferem valor moral às ações, mas eles certamente estão presentes.

\section{A crítica de Hegel à filosofia moral de Kant}

Hegel acusa Kant de cair em um "vazio formalismo" ou em uma "indeterminação abstrata", pelo fato de não considerar as circunstâncias em que ocorrem as ações e levar em conta, tão somente, a forma da lei (HEGEL, 1975, p. 166). Segundo ele, o imperativo categórico não enuncia o que deve ser feito, ou seja, não determina um conteúdo moral, podendo, nesse caso, ser usado tanto para justificar um ato moral como imoral. $\mathrm{O}$ teste da universalização é um teste puramente formal. Hegel insiste em dizer que Kant cai em uma "indeterminação abstrata", processo no qual nem sequer se passou pela mediação social. É uma moral do dever pelo dever, portanto, descontextualizada. O critério da não contradição reduz-se a uma "concordância formal" consigo mesmo. Para ele, o imperativo categórico deveria pressupor determinado conteúdo moral, para que então na sua aplicação pudesse ou não haver contradição. Haver ou não propriedade não implica em nenhuma contradição. Essa somente ocorre se houver um princípio que ordena o respeito à propriedade privada. Violá-la, então, é cair em uma contradição. A generalização de que todos podem negar um depósito que ninguém pode provar tem como consequência o desaparecimento dos depósitos. Mas isso só implica em contradição se houver um princípio prévio que prevê o respeito ao respectivo direito fundamental, no caso, o direito de propriedade.

É importante registar que o critério da não contradição é adotado e explicitado por Kant quando da primeira formulação do imperativo categórico ou mais especificamente nos exemplos referidos, quando da referência à lei universal da natureza. Cai em contradição quem reconhece a validade da lei moral, mas subjetivamente abre exceções a seu favor. Para Hegel, a contradição aí referida é apenas formal. Para ele, ocorre uma separação indevida entre forma e matéria da lei moral. Como poder-se-ia cair numa contradição se não houver a determinação de um conteúdo moral? A materialidade da lei é fundamental.

Hegel reconhece a importância da moral do dever pelo dever, a fim de resguardar a autonomia do sujeito agente. Mas trata-se de uma noção abstrata do dever, uma vez que não há definição de um conteúdo particular e um fim determinado. Toda ação exige um conteúdo particular, coisa que o dever pelo dever não faz. Hegel reconhece a importância da autodeterminação da vontade como "a raiz do dever", mas isso não passa de uma fundamentação subjetiva do dever, ou seja, Kant permanece "no mero ponto de vista da moralidade e não passa para conceito de eticidade" (HEGEL, 1975, p. 166). A moralidade kantiana, ao situar-se no plano do dever pelo dever, não trata das determinações objetivas da vontade livre.

Hegel pretende continuar onde Kant parou: a eticidade com suas determinações objetivas da liberdade - as mediações sociais. Para Hegel, o fato de permanecer no "mero ponto de vista mo-

\footnotetext{
4 O tema do construtivismo moral de Kant é amplamente abordado, por Rawls, em História da Filosofia Moral (2005, cap. VI) e O Liberalismo Político (2007, p. 144).
} 
ral", sem passar para o nível da eticidade, reduz a moral do dever pelo dever a um "vazio formalismo". Se partimos da "determinação do dever como ausência de contradição ou concordância formal consigo mesmo", caímos em uma "indeterminação abstrata", onde não se pode "passar para a determinação de deveres particulares" (HEGEL, 1975, p. 166). Para Hegel, não se age, pura e simplesmente, em cumprimento do dever pelo dever, mas se cumpre um dever por causa de um conteúdo. E como não há a determinação de um conteúdo, o procedimento pode ser usado para justificar qualquer um, ou seja, ora um, ora o seu contrário.

Em Sobre as maneiras de tratar cientificamente o direito natural (1979) Hegel, muito antes da Filosofia do Direito, faz uma dura crítica ao formalismo da moral kantiana. "Kant reconhece que a razão prática renuncia a toda a matéria da lei e que só a forma da máxima do livre-arbítrio pode converter-se em lei suprema. A máxima do livre-arbítrio tem um conteúdo e inclui em si uma determinidade" (HEGEL, 1979, p. 34). Ou seja, a máxima é o princípio subjetivo da ação. E continua Hegel: "Por outro lado, a vontade pura está livre de determinidades; a lei absoluta da razão prática consiste em elevar aquela determinidade à forma da unidade pura, sendo a lei a expressão dessa determinidade assimilada na forma" (HEGEL, 1979 , p. 34). Para ele, a lei é uma expressão formal de uma máxima (uma determinidade). Ela eleva a matéria (a máxima) à unidade da forma. A lei só diz o que é, ou seja, o que a máxima já dissera. Ela diz que o que é, deve ser. A universalidade formal não vai além da imediatidade da máxima. A lei resultante do teste formal da universalização seria uma mera proposição analítica e, portanto, não diz nada de novo. Ora, é preciso lembrar que Kant insiste na tese de que o imperativo categórico é uma proposição sintética a priori e não uma proposição analítica.

$\mathrm{Na}$ crítica hegeliana, o teste formal da universalização só funciona se já for conhecido um determinado conteúdo moral. A devolução de um depósito somente seria uma obrigação se houvesse a vigência de um princípio que prescrevesse essa exigência. Pode-se dizer que o assassinato é um crime somente sob a alegação de que isso não pode ser universalizado? Ou pode-se dizer que a máxima do assassino não pode ser universalizada pelo fato de já sabermos ser o assassinato um crime? Comentado a crítica de Hegel a Kant, afirma Seung: "Nosso julgamento moral desse ato precede o teste formal da universalização" (1994, p. 109). Nesse caso o imperativo categórico se tornaria dispensável. Aqui temos uma questão central: a aplicação do imperativo categórico pressupõe ou não um determinado conteúdo moral? Seu papel é somente justificar o que já é prática vigente?

Para Hegel, nesse teste formal, Kant estaria caindo em proposições tautológicas. Se houver propriedade, então deve haver propriedade. Se não houver o direito de propriedade legitimado, então admite-se a sua violação. Para Hegel, o interesse de Kant com o imperativo categórico é justificar aquilo que já é prática vigente para o "entendimento moral popular" (KANT, 1974a, p. 136). Ocorre que uma comunidade moral pode ter costumes, tradições e prerrogativas morais institucionalizadas de forma bem diferente de outra comunidade. Comunidades morais podem viver em ambientes sociais totalmente diferentes. Nos valeriamos, então, do imperativo categórico para justificar ora um determinado conteúdo, ora outro? Como definir aprioristicamente uma conduta moral? Além do mais, Kant está pressupondo que um mundo com propriedade privada é melhor do que um sem a propriedade privada. Ora, isso precisa ser demonstrado.

Honneth, ao comentar a crítica de Hegel à moralidade kantiana, salienta que uma das únicas formulações apropriadas e que merece ser considerada é a "objeção contra a cegueira em face do contexto" (HONNETH, 2007, p. 94). Diz Hegel estar visando com sua crítica:

enquanto abstrairmos o fato de que sempre nos movemos em um ambiente social no qual aspectos e pontos de vista já se encontram institucionalizados, a aplicação do imperativo categórico permanecerá ineficaz e vazia; mas se ao contrário aceitarmos a circunstância de que o ambiente social já sempre nos apresenta traços de deliberação moral, então o imperativo categórico perde sua função de fundamentação (HONNETH, 2007, p. 95). 
Em qualquer ambiente social encontramos principios, regras e doutrinas institucionalizadas. Honneth tem isso como um fato. Qual seria, então, o papel do imperativo categórico? Apenas justificar o que já é prática vigente? Não estaria Hegel adicionando circunstâncias que diz estarem faltando em Kant?

Honneth, tal como Hegel, esvazia o papel do imperativo categórico. De fato, se o ambiente social já sempre apresenta pontos de vista morais institucionalizados, o imperativo categórico tornar-se-ia dispensável. Ocorre que Hegel, e Honneth o acompanha, defende o desdobramento objetivo da liberdade em instituições sociais, o que Honneth chama de liberdade social. Isso ocorre na eticidade, que tem a função de propiciar uma "libertação do sofrimento de indeterminação", provocado pelos dois modelos incompletos de liberdade defendidos na modernidade, principalmente por Kant, a liberdade negativa e a liberdade optativa ou reflexiva. As normas de ação são resultado da mediação social. Em última instância, são conquistas da História. Nesse caso, a racionalidade está ligada ao processo de efetivação histórica. A razão perde a sua função de ditar as normas de ação. Haveria, aqui, um avanço em relação à fundamentação subjetiva da vontade livre em Kant? Do ponto de vista da eticidade, sim. A História é a evolução do grau de consciência da liberdade e de sua concretização. Essa é a dialética da História. Marx endossa essa tese.

\section{A crítica de Hegel depois de Rawls}

É comum a crítica de que Kant ignora as circunstâncias e as consequências das ações que envolvem valor moral. Que sua ética é formalista, apriorista e pouco realista. Hegel é um dos mais conhecidos desses críticos. Depois da interpretação de Rawls, sobretudo em História da Filosofia Moral, essa crítica precisa ser revista. Se as circunstâncias precisam ser consideradas na aplicação do procedimento do imperativo categórico, então a crítica hegeliana ao formalismo da moral kantiana ou de que há uma separação indevida entre forma e conteúdo da lei moral, não é devida. As máximas e as circunstâncias são o conteúdo ao qual o teste de universalização se aplica. As formulações do homem como fim em si mesmo e a da autonomia confirmam isso.

É preciso distinguir, afirma Bertomeu, as condições de inteligibilidade de um ordenamento e as condições de aplicabilidade do mesmo (1988, p. 39). Segundo a autora, Hegel as confunde. Uma coisa é o enunciado da lei moral, outra é a sua aplicação a uma determinada situação. O que deve motivar o sujeito agente é a universalidade da lei e não as possiveis consequências. É claro que estas não são ignoradas na aplicação da lei, mas não são elas que determinam o valor moral das ações. Rawls está se ocupando da aplicabilidade da lei moral, ou seja, ele faz com Kant o que fizera em sua teoria da justiça, isto é, distingue uma teoria ideal de uma teoria não ideal.

Portanto, faz parte da inteligibilidade de um preceito moral, levar em conta as circunstâncias. Por exemplo: a verdade sempre deve ser dita ou pode não ser dita em determinadas circunstâncias? "As condições que Hegel acrescenta ao ordenamento moral são, na verdade, supostos óbvios da inteligibilidade do mesmo" (BERTOMEU, 1988, p. 39). O que a prescrição "deves dizer a verdade" diz é que, "se para um ser racional em geral é dever dizer a verdade, em certas circunstâncias, então será dever para todos os seres racionais dizer a verdade em iguais circunstâncias" (1988, p. 39). Se é para proteger a vida de um inocente, aquele princípio pode permitir uma exceção. Nesse caso, o exemplo de Kant no texto "Sobre o suposto direito de mentir por amor a humanidade", é infeliz. Nessa situação, todos podem abrir uma exceção. Logo, não é mais exceção. Para proteger a vida de um inocente todos podem faltar com a verdade. Trata-se de uma circunstância que pode ser universalizada. O procedimento do imperativo categórico indica como a lei moral se aplica. Uma exceção não invalida a lei. Apenas mostra que ela não é absoluta. Nesse caso, Kant não cai em um mero legalismo. É preciso insistir em que apenas o procedimento é dado, mas o conteúdo moral é construido. Não se cumpre a lei pela lei (seja a lei positiva ou seja a lei moral), mas se cumpre ou não a lei pelo conteúdo por ela enunciado. 
A questão é: é um dever devolver um empréstimo nas circunstâncias $C$, isto é, estou em dificuldades e preciso de dinheiro, prometo devolvê-lo mesmo sabendo que não poderei fazê-lo? Nas circunstâncias citadas, a resposta de Kant é a de que devemos cumprir o prometido. A questão é saber se Kant admitiria situações nas quais é possivel faltar com a verdade. Segundo a interpretação de Rawls, essa hipótese deve ser possivel, caso contrário não faria sentido falar em circunstâncias $C$, mas simplesmente dizer que o dever de dizer a verdade vale aprioristicamente.

Se a interpretação de Rawls faz algum sentido, devem existir circunstâncias em que posso mentir, por exemplo, as de proteger a vida de um inocente. Nesse caso, Kant não cairia em um mero formalismo. São as circunstâncias que determinam a universalização ou não da máxima. Além do mais, Kant está pressupondo determinado conteúdo moral, tão reivindicado por Hegel: o princípio do dever de dizer a verdade. Logo, não cai em um "vazio formalismo". Aplicar o procedimento do imperativo categórico - o teste da universalização - significa especificar as circunstâncias. Um novo conteúdo moral é construido. O procedimento mostra como o imperativo categórico se aplica a nossa situação, ou como diz Rawls:

Esse procedimento especifica o conteúdo da lei moral tal como se aplica a nós enquanto pessoas razoáveis e racionais no mundo natural, dotadas de consciência e sensibilidade moral e afetadas, mas não determinadas, por nossos desejos e inclinações naturais (RAWLS, 2005, p. 189).

Revela-se, aqui, a necessidade da distinção entre inteligibilidade e aplicabilidade de um preceito moral, conforme o destaque de Bertomeu.

Para Rawls, Kant, com isso, quer mostrar que a aplicação do procedimento pressupõe "certa sensibilidade moral e uma capacidade de juízo moral" (RAWLS, 2005, p. 191). E o que significa ter sensibilidade moral? Significa dar-se conta de que pretender fazer uma promessa enganosa provoca uma questão moral: pode-se admitir essa promessa?

É claro que Kant deixa explícito que a promessa enganosa não poderia fazer parte do conjunto das leis da natureza que compõem o que Rawls chama de "mundo social ajustado". Se a promessa enganosa se tornasse lei da natureza, o mundo social seria inviabilizado. No entanto, a interpretação de Rawls mostra que se trata de uma promessa em determinadas circunstâncias, ou as "circunstâncias C". Isso não invalida o princípio de que a verdade deve ser dita. Ela só pode não ser dita em determinadas circunstâncias. No caso da proteção de um inocente, a mentira não se transforma em lei da natureza. O que ocorre é que nessas circunstâncias todos podem faltar com a verdade. E se mudarem as circunstâncias? Certamente vale a máxima que passou pelo teste da universalização e, assim, se transforma em lei. Mentir para proteger um inocente passa pelo teste de universalização, mas mentir para obter dinheiro emprestado não. Nesse caso, fica claro que o teste de universalização é um princípio de justificação. Mas não podemos abstrair as circunstâncias nesta justificação. Isso não invalida o princípio de que devemos dizer a verdade. Que a mentira seja admitida para proteger um inocente não universaliza a promessa enganosa.

O procedimento do imperativo categórico mostra como a lei se aplica a uma situação concreta. Daí a importância da explicitação das circunstâncias. Abrir uma exceção não significa uma relativização do princípio da verdade. É uma questão de inteligibilidade da lei.

Além do mais, considerando a ênfase rawlsiana na distinção entre lei moral e o procedimento do imperativo categórico, na medida em que neste explicita como o imperativo se aplica, tendo em vista determinadas circunstâncias, pode-se perguntar pela maior ou menor procedência da crítica hegeliana referente à "cegueira face ao contexto" da moralidade kantiana (HONNETH, 2007, p. 94). Ora, a lei moral se aplica a um determinado contexto, definido pelas circunstâncias das ações. Estará Kant ignorando que já sempre nos movemos em determinado ambiente social onde certos principios já estão institucionalizados? Mesmo que existam certos principios já institucionalizados, e eles existem, novas circunstâncias podem requerer nova interpretação. $O$ 
problema de Kant é um problema de construção e de justificação. O teste de universalização tem essa função. A ética é uma teoria da moral.

Uma critica consequencialista, como a de Hegel, dirá que Kant também ignora, além das circunstâncias, as consequências das ações. Ora, a posição de Kant é clara: não é o cálculo de possiveis consequências que confere valor moral às ações, mas a motivação delas. Paton diz que "Kant está correto em dizer que a expectativa das consequências não pode ser o fundamento determinante de uma ação se ela é para ter valor moral" (PATON, 1971, p. 76). O homem bom pergunta se a máxima de sua ação pode ser querida como lei universal. A máxima tem a seguinte forma, na interpretação de Paton: "Se estou em certas circunstâncias, realizarei uma ação provavelmente tendo em vista certas consequências" (PATON, 1971, p. 76). Como poderiamos agir se ignorássemos que toda ação tem consequências? Todavia, não julgamos nossas ações como corretas ou erradas em vista das consequências. Ocorre que estas podem ser necessárias ou totalmente contingentes. Necessárias quando são inerentes à própria ação, contingentes quando são totalmente imprevisiveis. $\mathrm{O}$ teste de universalização quer verificar se determinada ação é compativel com a natureza da lei universal. "Um homem bom visa as consequências por causa da lei: ele não obedece a lei simplesmente por causa das consequências" (PATON, 1971, p. 76).

Não há, portanto, em Kant, uma ignorância das consequências ou menosprezo por elas. Elas só não são determinantes na avaliação do mérito moral das ações. Mais importante do que um cálculo de possiveis consequências, o que dá valor moral às ações são as suas motivações. É claro que as melhores motivações podem resultar em consequências indesejáveis. Não há dúvida, no entanto, que, com a crítica de Hegel, verificamos que não basta uma ética das intenções. Precisamos, além disso, examinar os meios usados e as consequências e repercussões das ações. A ênfase de Kant, no entanto, é nas intenções. Na ausência dessas, todo juízo moral fica comprometido. Kant está perguntando se o sujeito sabia o que estava fazendo e quis fazer o que fez. Esse é o problema da responsabilidade moral. A análise desse problema precede a avaliação e a emissão de um juizo moral sobre as possiveis consequências. Um ato cometido por alguém que não sabia o que estava fazendo não é passivel de um juizo moral.

O valor moral das ações precisa repousar naquilo que o sujeito agente realmente quis fazer; naquilo que foi objeto explícito de sua vontade. Consequências não queridas e totalmente imprevisiveis, no mínimo, são atenuantes em um julgamento moral e inclusive legal.

Contra a critica de formalismo por parte de Hegel, deve-se registar que Kant não cai em proposições tautológicas. A lei resultante do teste de universalização não é mera proposição analítica. Trata-se da justificação de determinado conteúdo moral. A máxima é subjetiva, a lei é universal. É dito algo de novo. A máxima que passa pelo procedimento do imperativo categórico passa a ter validade e legitimidade. Ela se aplica a todos os seres racionais. O procedimento não é construido, mas as normas morais sim. Por isso que se pode falar em construtivismo moral, tal como Rawls fala em construtivismo político em sua teoria da justiça. ${ }^{5}$

Além do mais, não se pode ignorar a importância da terceira formulação do imperativo categórico: a do reino dos fins. Quando podemos querer que nossa máxima se converta em uma lei universal, assumimos a função de legisladores para um "reino dos fins", isto é, para uma comunidade moral. Legislamos para uma comunidade da qual fazemos parte, isto é, legislamos para nós próprios. Isso é autonomia. Respeitamos a lei da qual somos autores. Esse é o fundamento da dignidade e a base da democracia.

Na interpretação de Rawls, esse reino dos fins não está dado previamente e ao qual "nossa ação legisladora" deve harmonizar-se. A nossa ação legisladora "constrói a lei moral pública para um reino dos fins" (RAWLS, 2005, p. 234). Ao legislar,

\footnotetext{
5 Sobre o construtivismo moral kantiano na interpretação de Rawls, ver História da Filosofia Moral (2005, cap. VI) e O Liberalismo Politico (2007, p. 144).
} 
nós nos devemos ver como membros de uma comunidade moral da qual fazemos parte. Ora, Hegel parece ter ignorado essa formulação. Ele insiste no argumento da não contradição, referido nos exemplos da primeira formulação, como sendo meramente um critério formal, mas ignora que ocorre uma construção do conteúdo moral nessa terceira formulação. Hegel parece desconsiderar que o conteúdo moral é construído e que somente o procedimento é dado. O autor parece reduzir sua crítica à primeira formulação do imperativo categórico e não considera as demais formulações. A insistência no construtivismo moral kantiano é um importante legado da leitura rawlsiana.

A crítica à Kant de "vazio formalismo", presente na moral do dever pelo dever, está ligada a isso. O dever deve ser cumprido de forma totalmente desinteressada? Isso é possivel?

Com as distinções de Rawls acima referidas e o recurso a outros livros de Kant, além da Fundamentação da Metafísica dos Costumes e da Crítica da Razão Prática, tal como A Paz Perpétua, temos mais elementos que esclarecem essa posição. O autor reconhece que, de fato, uma ação inteiramente desinteressada não é possivel. "Concedo de bom grado que nenhum homem pode tornar-se consciente com toda a certeza de ter cumprido o seu dever de modo inteiramente desinteressado" (KANT, 1986, p. 68).

Mais uma vez é importante distinguir a lei moral e o procedimento do imperativo categórico. Se na prática, isto é, na aplicação, não é possivel uma ação totalmente desinteressada, o ideal é que seja assim. Caso contrário, não se poderia falar em moralidade ou em valor moral das ações. Ou somos capazes de abrir mão de muitos motivos que concorrem com a "ideia do dever" ou confessamos que nossas ações não têm mérito moral. Deveriamos cumprir o dever de forma desinteressada. Trata-se de um dever-ser. Para Kant, "que o homem deva cumprir o seu dever de modo totalmente desinteressado e deva de todo separar do conceito do dever a sua ânsia de felicidade para ter aquele em toda a sua pureza, disso ele é consciente com a máxima clareza" (KANT, 1986, p. 68, grifo do autor).
Kant quer, com isso, destacar o "valor da moralidade", que consiste exatamente nessa busca do dever desinteressado. Ainda que não totalmente possivel, esse é um ideal a ser buscado. E é nessa busca que está o valor moral das ações. O ser humano é capaz de agir por dever ou pelo menos ter consciência de que deve "tender" para isso, ou como diz o autor: "a máxima de tender para aquela pureza: disso é ele capaz" (KANT, 1986, p. 69). Aliás, é isso que the confere dignidade: a capacidade de exercer a autonomia. Estamos falando de mérito moral e não de ações meramente lícitas.

\section{Considerações finais}

A leitura rawlsiana de Kant em muito contribui com o esclarecimento de alguns aspectos objeto de muita divergência no contexto atual. $A$ distinção feita entre lei moral e o procedimento do imperativo categórico esclarece, em muito, o tão debatido formalismo da moral kantiana. Toda discussão sobre o apriorismo fica mais clara. Considerar a filosofia moral do filósofo de Koenisgberg como construtivista é outro aspecto esclarecedor. Falar em "imperativos categóricos particulares" mostra bem o que exatamente é construido e o que é simplesmente dado.

Merece destaque a importância dada ao procedimento do imperativo categórico e, por conseguinte, ao construtivismo moral. Tal como a posição original, esse procedimento é dado, mas o conteúdo da doutrina moral é construído. 0 conteúdo da lei moral, enquanto ideia da razão, é especificado pelo procedimento do imperativo categórico. O procedimento é sintético a priori e não é uma proposição analítica, conforme a crítica de Hegel. Pelo teste de universalização algo de novo é dito.

A leitura difundida de Kant é a de que o imperativo categórico vale independentemente das circunstâncias e que, por isso, seria pouco realista. A interpretação rawlsiana é esclarecedora quanto ao equívoco dessa leitura. Ela não distingue o imperativo categórico do procedimento do imperativo. É na sua aplicação que as circunstâncias devem ser consideradas. Não ocorre uma separação entre forma e conteúdo, 
mas uma distinção entre procedimento (formal) e o conteúdo construido. O preceito moral resultante do teste de universalização não é, portanto, uma proposição analitica.

A explicitação da aplicação do imperativo categórico, com ênfase no procedimento, a interpretação e a apropriação do tema da autonomia e a vinculação desta com a dignidade podem ser consideradas uma reatualização da Filosofia Moral kantiana. Isso torna ainda mais enfática a relevância desses temas para os debates atuais na Política, na Ética e na Bioética. Temos, aqui, também, elementos claros para a construção de um marco teórico que deveria pautar todas as nossas atividades pessoais e profissionais. Para quem trabalha diretamente com pessoas, como é o caso do Serviço Social, autonomia e dignidade são referenciais para uma atuação efetiva nos conflitos sociais e para uma conduta eticamente correta.

A distinção entre moralidade subjetiva e eticidade (moralidade objetiva) de Hegel, em muito contribuiu para a explicitação da Filosofia Prática de Kant. Uma análise da mediação social da vontade livre, suas repercussões e consequências, mostra bem os elementos subjetivos e os aspectos objetivos das ações a serem consideradas na emissão de um juizo moral. Uma ética das intenções não pode ser desvinculada de uma ética da responsabilidade. Para isso uma Filosofia das instituições sociais é indispensável. O Hegel dialético avançou onde Kant parou. Ele foi tão rico que provocou uma direita e uma esquerda. Nesta, Marx é o grande expoente. A construção de um marco teórico para - Serviço Social, a partir de Marx, se torna mais clara e convincente com o desenvolvimento e a explicitação da crítica de Hegel a Kant.

\section{Referências}

BERTOMEU, M. J. Recepción y vigência de la ética kantiana en el siglo xix y comienzos del xx. 1988. Tese (Doutorado em Filosofia) - Faculdade de Filosofia, Universidade de La Plata, La Plata, 1988.

HEGEL, G. W. F. Sobre las maneiras de tratar cientificamente el derecho natural. Madrid: Aguilar, 1979.

HEGEL, G. W. F. Grudlinien der Philosophie des Rechts. Frankfurt am Main: Suhrkamp, 1986.
HEGEL, G. W. F. Principios de la Filosofia del Derecho o Derecho Natural y Ciencia Politica. Traduzido por Juan Luis Vermal. Buenos Aires: Editorial Dudamericana, 1975.

HONNETH, A. Sofrimento de Indeterminação: uma reatualização da Filosofia do Direito de Hegel. São Paulo: Esfera Pública, 2007.

RAWLS, J. O Liberalismo Político. São Paulo: Martins Fontes, 2007

RAWLS, J. História da Filosofia Moral. São Paulo: Martins Fontes, 2005.

PATON, H. J. The Categorical Imperative: A Study in Kant's Moral Philosophy. Filadelfia: University of Pennsylvania Press. 1971.

KANT, I. Kritik der Praktischen Vernunft. Frankfurt am Main: Suhrkamp, 1974

KANT, I. Grundlegung zur Mataphysik der Sitten. Frankfurt am Main: Suhrkamp,1974.

KANT, I. A Paz Perpétua e outros opúsculos. Lisboa: Edições 70, 1986.

SEUNG, T. K. Kant's Platonic Revolution in Moral and Political Philosophy. London: The Hopkins V. Press, 1994.

WEBER, T. Ética e Filosofia Politica: Hegel e o formalismo kantiano. Porto Alegre: EDIPUCRS, 1999.

WEBER, T. Ética e Filosofia do Direito: autonomia e dignidade da pessoa humana. Petrópolis: Vozes, 2013.

\section{Thadeu Weber}

Doutor em Filosofia pela Universidade Federal do Rio Grande do Sul (UFGRS), em Porto Alegre, RS, Brasil; professor da Pontificia Universidade Católica do Rio Grande do Sul (PUCRS), em Porto Alegre, RS, Brasil.

\section{Endereço para correspondência}

Thadeu Weber

Pontificia Universidade Católica do Rio Grande do Sul Avenida Ipiranga, 6681, Prédio 11, 10 andar, sala 1053 Partenon, 90619-900

Porto Alegre, RS, Brasil

Os textos deste artigo foram revisados pela Poá Comunicação e submetidos para validação do autor antes da publicação. 